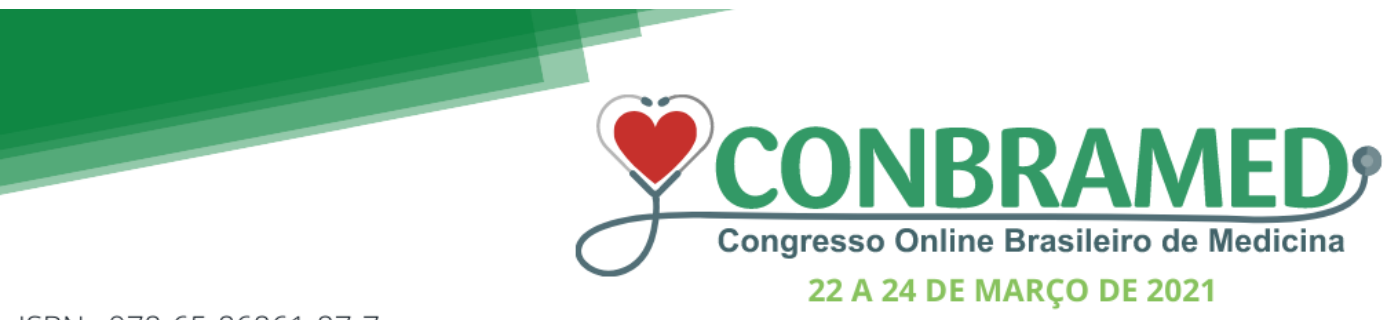

\title{
A IMPORTÂNCIA DA TERAPIA EXTRACORPÓREA POR ONDAS DE CHOQUE NO TRATAMENTO DA EPICONDILITE LATERAL: UMA REVISÃO DE LITERATURA
}

\author{
Congresso Online Brasileiro de Medicina, 1 ạ edição, de 06/12/2021 a 08/12/2021
}

ISBN dos Anais: 978-65-86861-87-7.

TOMAZ; Maria Vitória da Silva ${ }^{1}$, CARRARO; Cristiano Mayer dos Santos ${ }^{2}$, CUNHA; Marcos Guimarães de Souza ${ }^{3}$

\section{RESUMO}

A epicondilite lateral, também denominada "cotovelo de tenista", é uma patologia decorrente de repetitivos microtraumas e degeneração da origem tendínea do músculo extensor radial curto do carpo e extensor comum dos dedos. Devido ao fato de haver hipovascularização na inserção proximal tendínea, ocorrem degenerações acarretadas por hipóxia no tendão, as quais são secundárias à atividade muscular. Tal debilidade cursa com sensibilidade e dor ao redor do epicôndilo lateral em pacientes acometidos, sendo que há maior prevalência da patologia em indivíduos que praticam atividades repetitivas, baseadas em resistência e que realizam extensão do punho, visualizada na prática de modalidades esportivas, como no Tênis. É possível, então, empregar diferentes modalidades de tratamentos, sendo de formas não conservadoras, envolvendo técnicas invasivas, ou conservadoras, havendo a utilização de técnicas não invasivas, como na terapia extracorpórea por ondas de choque, a qual é o foco de abordagem do presente trabalho. Em tal forma de tratamento, utiliza-se um dispositivo eletromagnético ou eletrohidráulico, transmitindo ondas de pressão acústica de alta intensidade, sendo importante a utilização de gel na área corporal em foco, durante curto período de tempo. O trabalho tem o objetivo de demonstrar, qualitativamente, a importância e as vantagens atreladas à terapia extracorpórea por ondas de choque no tratamento da epicondilite lateral. Para isso, foi realizada uma revisão de literatura na base de dados PubMed, utilizando os descritores, em inglês, "Rehabilitation" and "Tennis elbow" and "Physical therapy". Os filtros utilizados foram Clinical Trial, Case Reports, Randomized Controlled Trial e Observational Study, aplicados para os últimos 5 anos (2016-2021). Nessa pesquisa foram encontrados um total de 45 artigos, dentre os quais foram selecionados apenas 7, com o critério de possuírem a terapia extracorpórea por ondas de choque como parte principal do tratamento da epicondilite lateral. Como resultado, foram encontrados benefícios como uma eficiente recuperação da musculatura e dos tendões, além da diminuição das dores, constatada a partir de duas ou três semanas após o início do tratamento em artigos científicos analisados, melhora significativa na funcionalidade da musculatura acometida pela epicondilite lateral e considerável estimulação da proliferação celular no local onde o tratamento foi aplicado. Alguns estudos também evidenciam um progresso significativo no processo de cicatrização dos tendões acometidos pela patologia, além de atuar induzindo a melhora da força de 
preensão, a qual é uma forma de avaliar a capacidade funcional da musculatura acometida, favorecendo a funcionalidade da musculatura extensora do punho e seus respectivos tendões. Conclui-se, portanto, de acordo com os artigos científicos utilizados como base para a realização do presente trabalho, que a terapia extracorpórea por ondas de choque como tratamento de epicondilite lateral mostra-se uma ferramenta de potente eficácia e benefícios notórios à qualidade de vida do paciente e melhora da patologia em questão, ressaltando a boa evolução do paciente, tendo em vista a diminuição, e cessão em alguns casos, dos sinais, sintomas e incremento da funcionalidade muscular e tendínea por meio do reparo eficiente aos danos causados pelos microtraumas repetitivos.

PALAVRAS-CHAVE: Cotovelo de tenista, Epicondilite lateral, Terapia extracorpórea por ondas de choque, Tratamento 